\title{
Familial dilated cardiomyopathy: a worse prognosis compared with sporadic forms
}

\author{
Miklós Csanády, Márta Hőgye, Árpád Kallai, Tamás Forster, Tamás Szárazajtai
}

2nd Department of
Medicine, Albert
Szent-Györgyi
Medical University,
Szeged, Hungary
M Csanády
M Högye
T Forster
T Szárazajtai
Department of
Radiology, Albert
Szent-Györgyi
Medical University,
Szeged, Hungary
Ả Kallai
Correspondence to:
Dr M Csanády, 2nd
Department of Medicine,
Albert Szent-Györgyi
Medical University, Szeged,
Korányi fasor 6, PO Box
480, Hungary 6701.
Accepted for publication
16 January 1995

2nd Department of

Medicine, Albert

Medical University,

Szeged, Hungary

M Högye

T Forster

T Szarazajtai

ent of

Medical University, Szeged, Hungary

Correspondence to: Dr Martmenty, 2nd Medical University, Szeged

16 January 1995

\begin{abstract}
Objective-To establish the time of onset of dilated cardiomyopathy (DCM) by review of annual chest $x$ rays, which are obligatory in Hungary.

Design-A retrospective survey of chest $x$ rays of a cohort of confirmed cases of DCM, to assess time of onset of cardiomegaly. Clinical course was compared by follow up over a mean of six years from the time of diagnosis.

Subjects-240 patients with DCM (31 familial, 209 non-familial). Diagnosis was made by echocardiography in all cases and confirmed by coronary angiography and heart biopsy in some cases.

Main results-At diagnosis, the mean age of the patients was 31.8 years in the familial group and 39.6 years in the nonfamilial group $(P<0.05)$. The time between the onset of cardiomegaly (cardiothoracic ratio $>0.45$ ) and clinical diagnosis was 8.0 and 10.1 years respectively $(P<$ $0.05)$. The six year survival was $6 \%$ in the familial group and $23 \%$ in the non-familial group $(P<0.05)$.

Conclusions-The familial form of DCM is the more malignant form: it occurs at an earlier age and progresses more rapidly than non-familial DCM.
\end{abstract}

(Br Heart $\mathcal{F} 1995 ; 74: 171-173)$

Keywords: familial dilated cardiomyopathy; sporadic cardiomyopathy; prognosis

Recent data ${ }^{1-3}$ show that familial dilated cardiomyopathy (DCM) is a not such a rare disease as was earlier believed. However, our knowledge about the age of onset of this form of cardiomegaly is limited as we only know the time of the onset of the clinical symptoms and signs of the disease. The clinical course of DCM is apparent only after the diagnosis has been made, while the real start of the disease before the onset of symptoms remains hidden. In Hungary, annual chest $x$ ray screening is obligatory, and we are therefore in a position to acquire information retrospectively on the earlier "latent" period of the disease. The changes in heart size of DCM patients can be analysed by means of the cardiothoracic ratio, and the extent of cardiomegaly can be characterised by the increase in the ratio. For this study, we selected patients on whom previous annual cardiothoracic ratio data were available. These patients were examined and fol- lowed very thoroughly, allowing us not only to determine the onset of cardiomegaly, but also to follow up the progression of the disease.

\section{Methods}

A comparison was made of 31 patients with familial DCM and 209 patients with sporadic DCM, for all of whom previous annual chest $x$ ray pictures were available. The familial DCM group consisted of 12 females and 19 males, while the non-familial group consisted of 68 females and 141 males. The cardiothoracic ratio was measured by the method of Groedel and Danzer, and values of $>0.45$ were taken as pathological. ${ }^{4-6} \mathrm{We}$ considered the disease to be of the familial form if we found at least two patients with frankly abnormal left ventricular function in the same family, and if at least two generations were involved. We recorded a detailed familial case history and examined all family members if possible. When relatives of DCM patients were not available for examination or were not alive, we asked for earlier medical reports, findings, and documentations. The diagnosis of DCM was made by echocardiography in all cases (M mode cross sectional colour coded Doppler echocardiography with a Toshiba 65A, ATLUltramark 9). Echocardiographic criteria of DCM was as follows: ejection fraction of the left ventricle (LVEF) < 52\%; diameter of the left ventricle in end diastole (LVEDD) $>55$ $\mathrm{mm}$. We measured the ejection fractions of the left ventricle by means of radionuclide ventriculography as well. A 12-lead electrocardiogram and a chest $x$ ray were taken in each case. In the event of any suspicion of rhythm disorders, we performed $24 \mathrm{~h}$ Holter monitoring. To exclude coronary artery disease, coronary angiography was used in 101 of the 240 patients: in 20 of the 31 familial cases, and in 81 of the 209 sporadic cases. Heart biopsy specimens were taken from the right ventricle by endomyocardial biopsy in 20 of the 31 familial cases, and in 78 of the 209 sporadic cases, and were examined by light and electronmicroscopy, including the direct immunofluorescence technique. We followed all 240 DCM patients regularly during a period of six years on average, performing echocardiography every three months, and radionuclide ventriculography at least annually. The clinical courses of the familial and non-familial forms of DCM were compared. The data were analysed statistically using the Fischer test, the Student $t$ test, and the Kaplan-Meyer method. 
Figure 1 The onset of cardiomegaly and the onset of symptoms in familial and non-familial cases of dilated cardiomyopathy (DCM) DG, diagnosis.

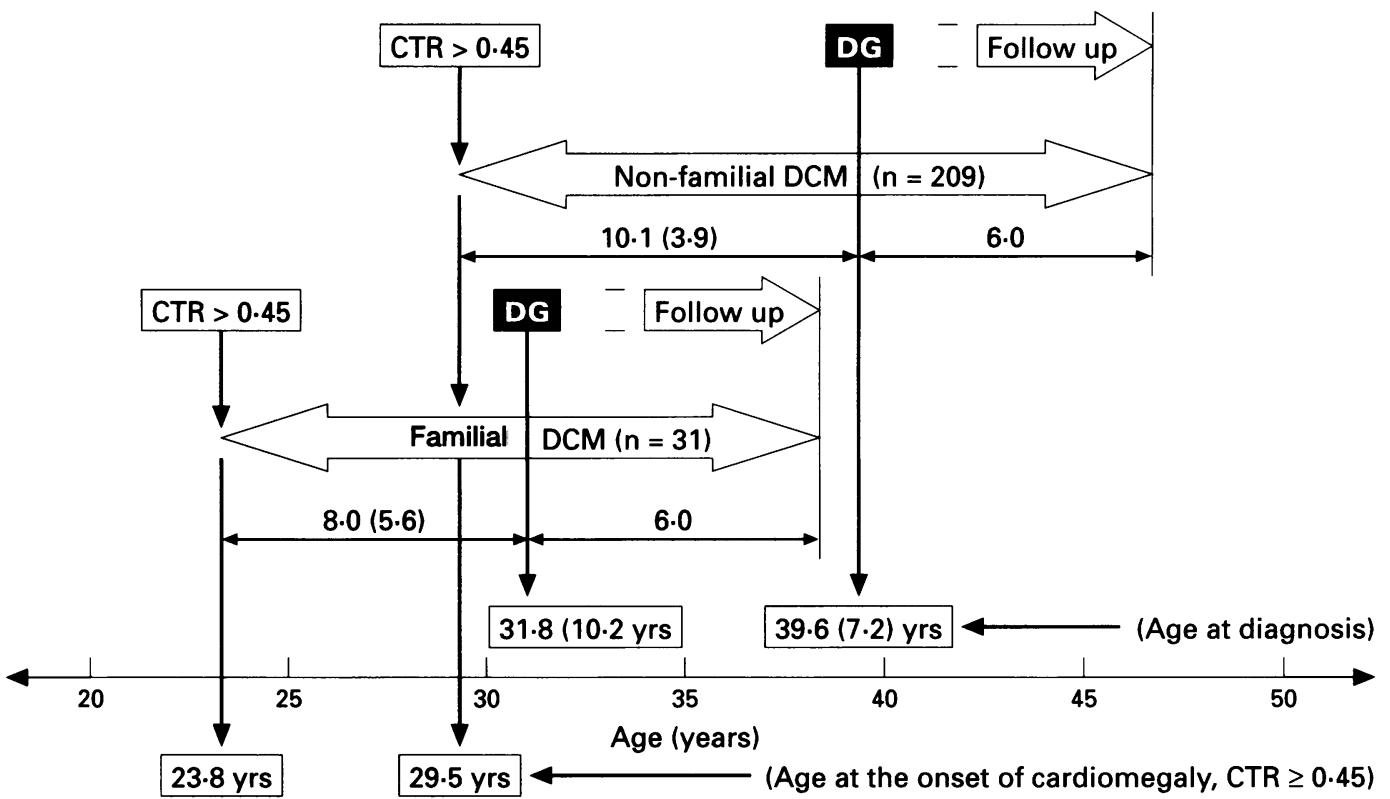

Figure 2 Survival of patients with dilated cardiomyopathies $(n=240)$. All differences were statistically significant.

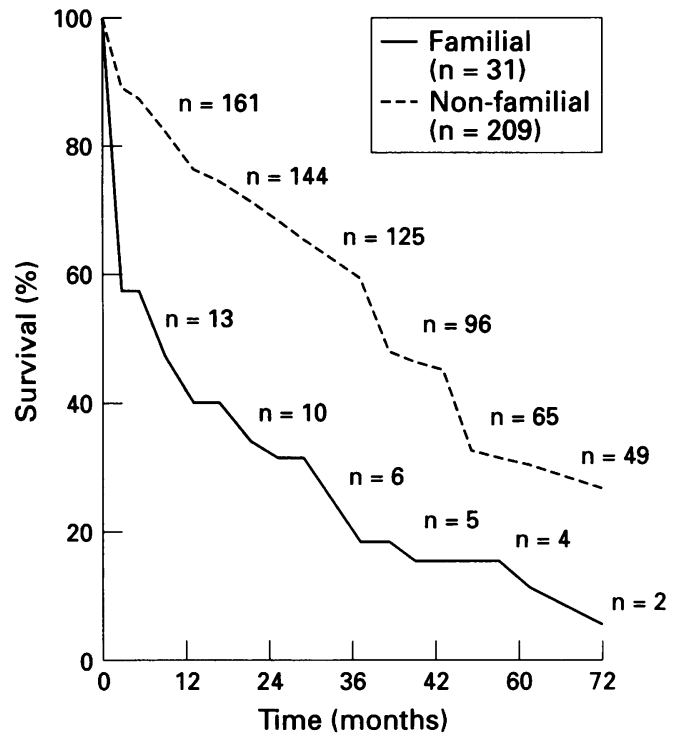

\section{Results}

At diagnosis, the mean age of the patients was 31.8 (SD 10.2) years in the familial group, and $39.6(7 \cdot 2)$ years in the non-familial group. In both groups, the onset of cardiomegaly preceded the onset of clinical symptoms and signs (that is, the diagnosis) by 8.0 $(5.6)$ and 10.1 (3.9) years, respectively, occurring at the age of 23.8 years and 29.5 years on average (fig 1 ).
Considerable differences were found in the survival rates of the patients, with four year survival rates of $9 \cdot 1 \%$ and $45.9 \%$, and six year survival rates of $6 \%$ and $29 \%$, in the familial and non-familial groups, respectively (fig 2). By the end of the six year follow up period, 29 of the 31 familial DCM patients had died ( $94 \%$ mortality), while 160 of the 209 patients in the non-familial group had died (77\% mortality) (table).

All the above mentioned differences were statistically significant $(P<0.05)$. The data show that the familial form of DCM is more malignant than the sporadic form; it occurs at an earlier age and progresses more rapidly.

\section{Discussion}

Familial DCM was previously considered to be a rare disease..$^{7-9}$ Our group was among the first to describe the existence of familial dilated (congestive) cardiomyopathy, and our interest has focused particularly on the familial form of the disease. ${ }^{1011}$ Detailed examination of the families of our familial DCM patients showed 31 families in which at least two (but frequently more) family members were involved. The incidence of the familial form was earlier found to be $21.5 \% .{ }^{12}$ Researchers from the Mayo group reported a similar incidence, ${ }^{13-15}$ and other investigators also believe that familial DCM is not rare. ${ }^{2316}$ At the time

Numerical data on the course of the familial and non-familial forms of dilated cardiomyopathy (DCM). Values are means (SD)

\begin{tabular}{lllllll}
\hline & $\begin{array}{l}\text { Age at the } \\
\text { beginning of } \\
\text { cardiomegaly } \\
\text { (CTR }>0.45) \\
\text { (years) }\end{array}$ & $\begin{array}{l}\text { Latent period } \\
\text { from the start } \\
\text { of cardiomegaly } \\
\text { till the diagnosis } \\
\text { (years) }\end{array}$ & $\begin{array}{l}\text { Age at the onset } \\
\text { of symptoms, ie } \\
\text { on diagnosis } \\
\text { (years) }\end{array}$ & $\begin{array}{l}\text { Follow up } \\
\text { time } \\
\text { (years) }\end{array}$ & $\begin{array}{l}\text { Total duration } \\
\text { of the disease } \\
\text { from CTR }>0.45 \\
\text { till present (years) } \\
\text { Latent period }+ \\
\text { follow up }\end{array}$ & Mortality (\%) \\
\hline $\begin{array}{l}\text { Familial DCM } \\
\text { (n=31) }\end{array}$ & $23.8(6.3)$ & $8.0(5 \cdot 6)$ & $31.8(10.2)$ & $6.0(2.4)$ & $13.0(7 \cdot 2)$ & $94(29 / 31)$ \\
$\begin{array}{l}\text { Non-familial } \\
\text { DCM (n=209) }\end{array}$ & $29.5(9.2)$ & $10.1(3.9)$ & $39.6(7.2)$ & $16.1(3.8)$ & $77(160 / 209)$ \\
\hline
\end{tabular}


Enlargement in heart size of a patient with dilated cardiomyopathy

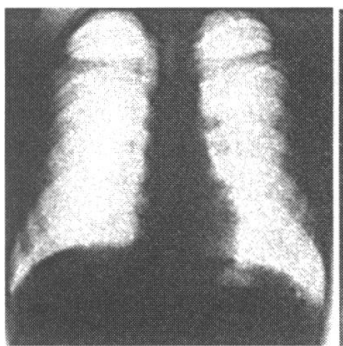

1981

CTR $=0.36$

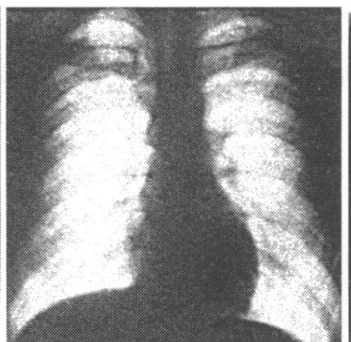

1983

$\mathrm{CTR}=0.38$

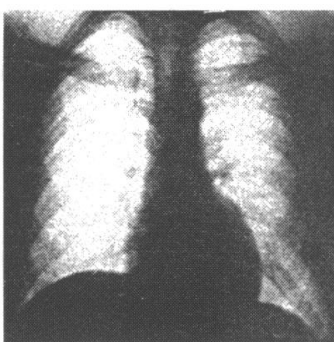

1987

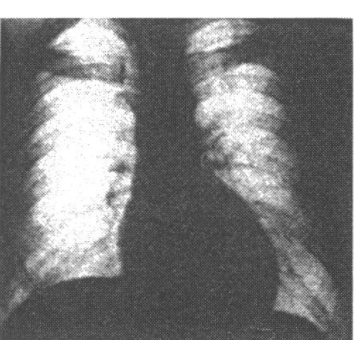

1989

$\mathrm{CTR}=0.43$

$\mathrm{CTR}=0.47$

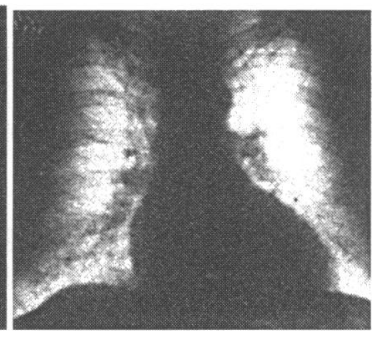

1992

Figure 3 Example of enlargement in heart size of one of our patients with dilated cardiomyopathy.

the complaints and symptoms occur and the diagnosis is made, only the tip of the iceberg can be seen; the point at which the disease began is unknown, and the onset of the cardiomegaly is likely to be an earlier manifestation than the symptoms. In Hungary, annual chest $x$ ray screening for pulmonary tuberculosis is obligatory, and thus a good opportunity was available for us to study heart size retrospectively by measuring the cardiothoracic ratio and thereby obtain information on the previous latent period of the disease. Figure 3 shows a series of annual chest $x$ ray pictures from one of our familial DCM patients. It is obvious that the increase in heart size was gradual, and the "latent" period lasted for 11 years in this case.

In both familial and non-familial DCM, the cardiomegaly (cardiothoracic ratio $>0.45$ ) preceded the onset of the first complaints by 8-10 years. These findings are of interest. First, they show that the influenza-like complaints around the time of the diagnosis are not of great importance, as might once have been thought. Secondly, the objective cardiothoracic data prove that the onset of cardiomegaly occurs at a younger age in familial DCM cases than in the non-familial form. It is by no means certain that familial congestive cardiomyopathy is a completely uniform disease; with expanding knowledge, further subgroups may well be distinguished in the future.

The contribution of a genetic factor to the development of familial DCM has recently been discussed, with the conclusion that genetic transmission is detectable in over $20-25 \%$ of the patients. ${ }^{13} 17$ The introduction of molecular genetics into the study of familial cardiomyopathies has given further support to the hypothesis of the heterogeneity of the dilated form. Besides the earlier manifestation of the familial form, its progression is also more rapid than in the non-familial cases. The clinical significance of this observation is that the rapid progression of familial DCM should be taken into consideration in scheduling heart transplantation. ${ }^{18}$

1 Mestroni L, Krajinovic M, Severini GM, Pinamonti B, Di Lenarda A, Giacca $M$, et al. Familial dilated cardiomyopathy. Br Heart $\mathcal{f}$ 1994;72 (Dec suppl):35-41.

2 Zachara E, Caforio ALP, Carboni GP, Pellegrini A, Pompili A, Del Porto G, et al. Familial aggregation of idiopathic dilated cardiomyopathy: clinical features and pedigree analysis in 14 families. Br Heart $\mathcal{f} 1993 ; 69$ : 129-35.

3 McKenna WJ. Familial dilated cardiomyopathy-not so rare. Br Heart $\mathcal{F} 1992 ; 67: 324-8$.

4 Danzer C. The cardiothoracic ratio, an index of enlargement. Am F Med Sci 1991;157:513.

5 Groedel FM. Vereinfachte Ausmessung des HerzOrthodiagramms nach theo Groedel. Munch Med Wochenschr 1918;65:397.

6 Fráter L, Bali I, Kelemen J, Mizsei I, Csanády M, Hőgye M. A szívnagyság idóbeli alakulása congestiv cardiomyopathiában. Orv Hetil 1983;124:2535-40

7 Braunwald E. Heart disease: a textbook of cardiovascular medicine, 3rd ed. Philadelphia: WB Saunders, 1988.

8 Goodwin JF. Function in primary myocardial disorders. $B M \mathcal{F} 1964: 1527$ and 1595.

9 Goodwin JF, Oakley CM. The cardiomyopathies. Br Heart f 1972;34:545-9.

10 Csanády M, Szász K. Familial cardiomyopathy. Cardiology 1976;61:122-30.

11 Emanuel R. Familial cardiomyopathies. Postgrad Med $\mathcal{f}$ 1972;48:742-5.

12 Csanády $M$, Faragó $M$, Forster $T$, Högye $M$, Piros Gy. Study of the course of inheritance of dilated familial cardiomyopathy (abstr). Eur Heart ₹ 1991;12:191 (P 1039).

13 Michels VV, Moll PP, Miller FA, Tajik AJ, Chu JS, Driscoll DJ, et al. The frequency of familial dilated cardiomyopathy in a series of patients with idiopathic dilated cardiomyopathy. $N$ Engl F Med 1992;326:77-82.

14 Michels VV, Driscoll DJ, Miller FA. Familial aggregation of idiopathic dilated cardiomyopathy. $\mathrm{Am} \mathscr{\mathcal { F }}$ Cardiol 1985;55:1232-3.

15 Michels VV, Moll PP, Miller FA, Tajik AJ, Chu JS, Driscoll DJ, et al. The frequency of familial dilated cardiomyopathy in a series of patients with idiopathic diomyopathy in a series of patients with idiopathic
dilated cardiomyopathy. $N$ Engl $f \mathrm{Med} 1992 ; 326: 77-82$.

16 Mestroni L, Miani D, Di Lenarda A, Silvestri F, Bussani R, Filippi G, et al. Clinical and pathologic study of familial dilated cardiomyopathy. Am $f$ Cardiol 1990;65: 1449-53.

17 Keeling PJ, McKenna WJ. Clinical genetics of dilated cardiomyopathy. Herz 1994;19:91-6.

18 Valentine HA, Hunt SA, Fowler MB, Billingham ME Schroeder JS. Frequency of familial nature of dilated cardiomyopathy and usefulness of cardiac transplantation in this subset. Am $₹$ Cardiol 1989;63:959-63. 